\title{
JUSTIÇA E EQUIDADE COMO ELEMENTOS BASILARES PARA O DESENVOLVIMENTO DE MEIOS ADEQUADOS À CONCRETIZAÇÃO DO ACESSO À JUSTIÇA
}

\author{
Aldo Aranha de Castro ${ }^{1}$ \\ Ynes da Silva Félix ${ }^{2}$
}

\begin{abstract}
Resumo: O presente trabalho tem por escopo abordar o tema da justiça e da equidade, bem como apresentar mecanismos para concretizar o acesso à justiça. Por esse motivo, serão apresentadas teorias acerca da justiça, desenvolvendo o estudo de forma sempre alinhada aos direitos humanos, pois o conceito de justiça (e a concretização do acesso à justiça) não tem o seu valor se não for possível preservar a dignidade da pessoa humana. A presente pesquisa apresenta a metodologia dedutiva para o seu desenvolvimento, com base em doutrina e artigos científicos para ser alicerçada.
\end{abstract}

Palavras-chave: Justiça; Equidade; Mecanismos adequados de solução de conflito; Mediação; Conciliação.

\section{JUSTICE AND EQUITY AS BASIC ELEMENTS FOR THE DEVELOPMENT OF APPROPRIATE MEANS TO CONCRETIZE THE ACCESS TO JUSTICE}

\begin{abstract}
This paper aims to approach the theme of justice and equity, as well as to present mechanisms to concretize the access to justice. Therefore, theories about justice will be presented, developing the study aligned with human rights, because the concept of justice (and the concretization of the access to justice) doesn't have its value if it isn't possible to preserve the human person dignity. This research presents the deductive methodology for its development, based on doctrine and scientific articles.
\end{abstract}

Keywords: Justice; Equity; Appropriate mechanisms of conflict resolution; Mediation; Conciliation.

\section{Introdução}

Um dos temas mais difíceis (se não o mais difícil) para se abordar é o que diz respeito à justiça (que traz consigo a questão da equidade), pois muitas são as vertentes

\footnotetext{
${ }^{1}$ Doutorando em Direito - Universidade de São Paulo - USP (DINTER USP-UFMS). Mestre em Direito pela da Universidade de Marília - UNIMAR. Especialista em Direito Civil e Processo Civil pela UEL/PR. Graduado em Direito pela Universidade de Marília (UNIMAR). Professor Assistente da Universidade Federal de Mato Grosso do Sul - UFMS, Campus de Três Lagoas. Mediador e Conciliador Judicial cadastrado no Tribunal de Justiça do Estado de Mato Grosso do Sul. E-mail: aldodecastroadv@hotmail.com / aldo.aranha@ usp.br .

${ }^{2}$ Doutora em Direito pela Pontifícia Universidade Católica de São Paulo (PUC-SP). Mestre em Direito pela Pontifícia Universidade Católica de São Paulo (PUC-SP). Graduada em Direito pela Universidade Católica Dom Bosco (UCDB). Professora permanente do Programa de Mestrado em Direito da Universidade Federal de Mato Grosso do Sul (UFMS). Diretora e Professora Titular da Faculdade de Direito da Universidade Federal de Mato Grosso do Sul (UFMS). E-mail: ynesil@ hotmail.com .
} 
conceituais que o tema pode apresentar, e o que se considera justiça para um, pode não o ser para outro. Nesse sentido, alguns problemas surgem e precisam ser resolvidos ou, pelo menos, esclarecidos, para que a sociedade viva em harmonia e se satisfaça com a solução adotada.

Num primeiro momento, é necessário esclarecer que a justiça não deve simplesmente garantir o reinado pleno e soberano da maioria, enquanto a minoria fica completamente subjugada no meio social; pelo contrário, deve-se possibilitar a participação da minoria, que deve ser ouvida, e não cerceada em seus direitos e possibilidades de manifestação.

A Constituição Federal da República Federativa do Brasil, de 1988, traz diversos fundamentos, dentre os quais merece destaque a dignidade da pessoa humana (art. $1^{\circ}$, inciso III), tida como um sobreprincípio, com o qual se coaduna o entendimento, e que deve ser respeitado e preservado por todos. Todavia, em 2018, a Constituição Federal completou trinta anos, há pontos que merecem ser comemorados, mas ainda há muito a se conquistar para uma comemoração completa, pois diversos preceitos nela contidos ainda não podem ser observados, e alguns não são praticados, quer porque parte deles ainda não esteja à disposição da sociedade, quer porque a totalidade dele ainda sequer saiu do papel.

Desta feita, é essencial observar diversos aspectos para se compreender o que é justo, qual o senso de justiça, de que modo compreender a equidade, e como aplica-los de forma empírica, para a preservação da garantia de tutela jurisdicional à sociedade. Deve-se atentar, também, à justiça como razão de decidir, onde guarda relação próxima com o Poder Judiciário e com novos institutos, surgidos (e alguns, já existentes, que ganharam força) para que o acesso à justiça seja deveras garantido, como são os casos da conciliação e da mediação.

O próprio Código de Processo Civil (Lei n. ${ }^{\circ}$ 13.105, de 16 de março de 2015) incorporou, em seus dispositivos atuais, muitos preceitos constitucionais que, embora antes já fossem adotados de forma implícita, agora se tornaram expressos em seus dispositivos, como é o caso da dignidade da pessoa humana (art. $8^{\circ}$ ).

Para se compreender melhor os conceitos de justiça e sua evolução, não se pode deixar de lado as garantias inerentes ao ser humano, e que são tão defendidas, nacional e internacionalmente, pelos direitos humanos.

Tais garantias foram se positivando, com o objetivo de preservar a efetividade dos direitos humanos, e seu pleno exercício. Assim, é possível observar três gerações de direitos humanos, sendo que a primeira é pautada nos direitos de liberdade, a segunda nos direitos de igualdade e, por fim, a terceira geração tem como valor preponderante a solidariedade (esta 
última, entre outros, traz como conteúdo os direitos à paz). Para que os direitos humanos, e esses valores estabelecidos nas gerações, sejam preservados na íntegra, e realmente efetivados, é preciso garantir a justiça e, até mesmo, antes disso, o acesso à justiça, também previsto constitucionalmente (art. 5, inciso XXXV, CF/88), a todos os cidadãos.

O presente trabalho se justifica em razão da complexidade em se abordar esses temas, por vezes tão delicados - justiça, equidade e mecanismos para alcançar o acesso à justiça - e, assim, tem-se por objetivo realizar uma análise pontual sobre esses conceitos, para que se propicie uma melhor compreensão sobre eles e, ao fim, seja possível indicar mecanismos (tais como a conciliação e a mediação) que sirvam para a concretização do acesso à justiça. Por meio do método dedutivo, e através de pesquisa bibliográfica (estruturada em doutrinas e artigos científicos), pretende-se proporcionar uma reflexão acerca dos conceitos trazidos (em especial o de justiça) para que, através de um raciocínio crítico, haja a compreensão adequada do tema proposto.

\section{Uma abordagem moderna e conceitual de justiça}

A realização da justiça é um fim buscado por todos que estudam o Direito, e também pela sociedade, que anseia um ambiente de pacificação e harmonia. Para que essa ideia se materialize, faz-se importante compreender a noção de justiça, que é possível encontrar na Constituição Federal, e estruturar o que sua ideia pretende transmitir pois, somente com essa compreensão, será possível adentrar em alguns meios para que a justiça seja concretizada.

A CF/88 traz em seu corpo, em diversas passagens, o termo justiça. Em muito deles, para indicar os aspectos procedimentais, e os órgãos e funções do Poder Judiciário. Já para o estudo em comento, são três as menções à justiça que merecem destaque, sendo a primeira, no preâmbulo que, embora não tenha força normativa, traz valores a serem analisados e, muitos deles, resguardados pelas normas de direitos humanos.

Para se ter uma ideia, nele constam as gerações de direitos humanos já mencionadas, quais sejam, a liberdade, a igualdade e a fraternidade (solidariedade), daí não se pode menosprezar o que consta no preâmbulo, pois encontra respaldo em diversas normas, tanto nacionais quanto internacionais de direitos humanos, inclusive, com a solução pacífica das controvérsias, que pode se dar, entre outros meios, através da conciliação e da mediação.

A segunda menção de justiça consta no artigo 170, e a terceira, no artigo 193 do texto constitucional, que dispõem da seguinte forma: 
Art. 170. A ordem econômica, fundada na valorização do trabalho humano e na livre iniciativa, tem por fim assegurar a todos existência digna, conforme os ditames da justiça social, observados os seguintes princípios [...]

[...]

Art. 193. A ordem social tem como base o primado do trabalho, e como objetivo o bem-estar e a justiça sociais. (grifo nosso)

Não apenas o preâmbulo destaca o termo justiça. Há dois artigos (portanto, com força normativa) que também o fazem. O artigo 170 guarda relação com a ordem econômica e financeira, devendo-se garantir a justiça social para que a sociedade tenha assegurada uma existência digna (o que coaduna com a dignidade humana). Já o artigo 193 diz respeito à ordem social, e tem como um de seus objetivos a justiça social. Desse modo, o principal diploma normativo brasileiro busca o respeito e a proteção à justiça, com o fim de abranger toda a sociedade, garantindo a dignidade da pessoa enquanto ser humano.

Além da Constituição brasileira, diversos textos normativos, da legislação pátria e estrangeira, bem como tratados internacionais, visam à proteção da justiça, e a garantia da equidade para a coletividade. Não se pretende esgotar o conceito de justiça, até em razão de sua amplitude, nem estabelecer um conceito único, ou uma verdade absoluta do que o seja, mas sim, apresentar uma análise fundamentada sobre o tema e o conceito de justiça, pautando-se em teóricos que buscam, de fato, transmitir aquilo que entendem como o correto para a justiça propiciando, com isso, uma reflexão crítica.

Assim, Aristóteles (apud GONÇALVES JR., 2012, p. 213), em seu tempo, afirmava que "a justiça é uma igualdade e a injustiça uma desigualdade", e a justiça era tida como um "hábito" onde, se houvesse o tratamento igualitário, ela seria alcançada, caso contrário, estarse-ia em sentido exatamente oposto. No mesmo sentido, de aproximar a justiça da igualdade, Jerson Carneiro Gonçalves Jr. (2012, p. 212) diz que "a igualdade é elemento essencial e básico do conceito estrito de justiça", e reforça os ensinamentos de São Tomás de Aquino, para quem "a essência da justiça é a igualdade". Nesse contexto, a justiça deve estabelecer e proteger a igualdade entre as partes, e o juiz deve garantir que tal equilíbrio aconteça.

A doutrina aristotélica (GONÇALVES JR., 2012, p. 214) traz algumas classificações quanto às espécies de justiça, definindo que a justiça particular (que tem por objeto o bem particular) se divide de algumas formas específicas, como a comutativa, a distributiva, a geral (ou social), a vindicativa e a "noção perfeita de justiça". Desse modo, há uma gama de virtudes contempladas pela justiça, tais como o equilíbrio, o respeito e a igualdade, não 
podendo uma parte levar vantagem, pois estão em equilíbrio, devendo ser tratados de igual modo, e com igual respeito, punindo-se os excessos e o tratamento desequilibrado.

Inclusive, para reforçar e fechar essa ideia, Aristóteles (apud FERRAZ JÚNIOR, 2009, p. 182), em sua obra Ética a Nicômano, traz uma definição de virtude, como sendo a “disposição de agir de modo deliberado, consistindo em um meio-termo relativo a cada um, racionalmente determinado e como o determinaria o homem prudente”. Dentro desse pensamento, em cada caso deve ser feita a reflexão para garantir a proteção de todos, e a pessoa, dentro do agir racional, deve fazer uso da ponderação para praticar ou não determinado ato, para fazer ou não determinada coisa.

Analisando as ideias de Aristóteles, Tércio Sampaio Ferraz Júnior (2009, p. 197) diz que "é estudando as ações dos homens justos que se chega a conhecer a justiça", e complementa, ao explicar que “diz, pois, Aristóteles que se o homem injusto é geralmente aquele que viola a lei e aquele que toma mais do que lhe é devido, faltando para com a igualdade, o homem justo será, ao revés, o que age conforme à lei e respeita a igualdade".

Além dessa, existem outras várias visões acerca da justiça e que merecem análise. Para deixar claro que a justiça não traz uma única significação e análise, ela também pode ser apreciada em correlação com o Poder Judiciário e, nesse ponto, trazer a ideia de razão de decidir. Tércio Sampaio Ferraz Júnior (2009, pp. 270-271) traz uma análise acerca de José Frederico Marques, e identifica essa razão:

[...] dirá ele, repetindo seu mestre Enrico Tullio Liebman, que a Justiça (Poder Judiciário), na mesma proporção que é um bem indispensável à sociedade, constitui garantia da liberdade do indivíduo, seja no confronto com o arbítrio da autoridade, seja na relação com outros indivíduos. Por isso, na garantia da liberdade, a independência jurídica do juiz exige a independência política.

O juiz, então, precisa ter independência para que não ocorra uma ditadura, onde as liberdades seriam severamente cerceadas, e o direito, uma mera reprodução de leis (com requintes de crueldade). O magistrado deve ter liberdade para, respeitando a lei, adotar a posição mais justa para o caso concreto (que deverá ser analisado com suas peculiaridades).

Outros significados de justiça também merecem o estudo, para viabilizar a extração de sua essência e a melhor compreensão do tema. Para Platão (apud FERRAZ JÚNIOR, 2009, p. 171), "a justiça passa [...] a ser, portanto, o princípio regulador da vida individual, da vida social e de todo o universo" e, assim, ela se torna a chamada justiça universal. Guarda relação 
com essa ideia a análise de Tércio Sampaio Ferraz Júnior (2009, p. 216), para quem "o justo, conforme à justiça universal, corresponde ao que é conforme a lei, e o injusto, conforme à injustiça universal, corresponde ao que é contrário à lei”.

A amplitude da justiça pode ser observada nos dizeres de John Rawls (2000, p. 03): “A justiça é a primeira virtude das instituições sociais, como a verdade o é dos sistemas de pensamento". Não se pode restringir essa análise a uma definição apenas, porque se incorreria no pior dos erros, qual seja, trazer uma "verdade absoluta", por isso, a intenção é apresentar as diversas vertentes, possibilitando o estudo por parte de todos, para formar uma convicção.

Não se pode dispor de conceitos como justiça e verdade, destacados por John Rawls, pois são inerentes a cada pessoa. Dispor de um deles, ou de ambos, seria agredir à dignidade humana, posto que o mundo viveria num sistema de injustiças, onde enganar a sociedade seria um passo para se alcançar o que se quer (e isso foge à noção do justo). Então, é possível tolerar alguma injustiça? “[...] uma injustiça é tolerável somente quando é necessária para evitar uma injustiça ainda maior" (RAWLS, 2000, p. 04). A resposta, assim, é no sentido de minimizar a injustiça, se sopesar entre uma injustiça e outra, ambas inevitáveis, deve-se buscar a que minimize os danos (ou atenue para que essa situação possa ser, se não corrigida por completo, levada às menores ou ínfimas consequências). Ele complementa dizendo que:

Para nós, o objeto primário da justiça é a estrutura básica da sociedade, ou mais exatamente, a maneira pela qual as instituições sociais mais importantes distribuem direitos e deveres fundamentais e determinam a divisão de vantagens provenientes da cooperação social. Por instituições mais importantes quero dizer a constituição política e os principais acordos econômicos e sociais. (RAWLS, 2000, pp. 07-08).

Da narrativa acima, rememora-se à Constituição Federal que, no artigo 170, traz a questão da justiça social aliada à ordem econômica e financeira e, um dos aspectos específicos é o que se relaciona à redução das desigualdades regionais e sociais. Assim, deve-se buscar a preservação e um tratamento igualitário, de modo a se propiciar a todos o mesmo acesso, a mesma oportunidade, a mesma proteção, para a atual e as futuras gerações.

Dois princípios da justiça são trazidos por John Rawls (2000, p. 57), que destaca: “O primeiro objeto dos princípios da justiça social é a estrutura básica da sociedade, a ordenação das principais instituições sociais em um esquema de cooperação". E daí, tece comentário mais detalhado dos princípios que são conhecidos como da igual liberdade e da eficiência: 
Primeiro: cada pessoa deve ter um direito igual ao mais abrangente sistema de liberdades básicas iguais que seja compatível com um sistema semelhante de liberdades para as outras. Segundo: as desigualdades sociais e econômicas devem ser ordenadas de tal modo que sejam ao mesmo tempo (a) consideradas como vantajosas para todos dentro dos limites do razoável, e (b) vinculadas a posições e cargos acessíveis a todos. (RAWLS, 2000, p. 57).

Dessa análise do autor em comento pode-se compreender que, no primeiro princípio, é abordada a igual liberdade, no sentido de assegurar liberdades básicas iguais para todos. Já no segundo, há um contraponto, onde num primeiro momento é possível se observar a questão das diferenças, com o anseio pela possibilidade de vantagem para todos e, no segundo estágio, traz alusão a uma igualdade de oportunidades, aproximando ao que existe hoje no artigo 170 da $\mathrm{CF} / 88$, quando aborda a justiça social e traz hipóteses em que se deve buscá-la.

Essa ideia é corroborada por Paul Ricoeur (1995, p. 91), ao dizer que "esses princípios são chamados de igual liberdade (1), diferença (2a) e igualdade de oportunidades (2b) (itálico do autor)". Assim, o segundo princípio é dividido em dois momentos, e referido autor (1995, pp. 91-92) ainda faz uma explicação sobre tais princípios, que merece destaque:

O primeiro princípio assegura, como é evidente, as liberdades iguais da cidadania (liberdade de expressão, de reunião, de voto, de elegibilidade para funções públicas). [...] Poderíamos resumir a questão nestes termos: poderse-á falar, com toda a equidade, de desigualdades mais justas ou, pelo menos, menos injustas que outras? Donde o segundo princípio de justiça: ele estabelece, na sua primeira parte, as condições sob as quais as desigualdades devem ser consideradas como preferíveis a desigualdades maiores, mas também a uma repartição igualitária, donde o nome de princípio de diferença; na sua segunda parte, igualiza tanto quanto possível as desigualdades ligadas às diferenças de autoridade e de responsabilidade. $\mathrm{O}$ princípio de diferença selecciona assim a situação mais igualitária compatível com a regra de unanimidade. Tão importante como o conteúdo desses princípios é a regra de prioridade que os liga um ao outro. (itálico do autor)

Com isso, pode-se observar que a interpretação desses princípios deve ser feita, sempre que possível, interligando-os, para constituir um alicerce mais firme ao conceito de justiça. Já na obra “O Justo 2”, Paul Ricoeur (2008, p. 252) acaba reforçando algumas noções acerca da justiça, e a transição da justiça apenas como virtude, para a justiça como instituição:

Ninguém está autorizado a fazer justiça com as próprias mãos; assim reza a regra de justiça. Ora, é em benefício de tal distância que se faz necessário um terceiro, uma terceira parte, entre o ofensor e sua vítima, entre crime e castigo. Um terceiro como avalista da justa distância entre duas ações e dois agentes. 
É o estabelecimento dessa distância que requer a transição entre a justiça como virtude e a justiça como instituição.

Em consequência disso, tem-se a justiça como a razão de decidir, onde um terceiro participará para auxiliar as partes e, em não havendo consenso, fará prevalecer sua decisão. Essa figura do terceiro pode advir das leis, ou mesmo do Poder Judiciário, que decidirá e, assim, tentará evidenciar a justiça em relação ao caso concreto a ser apresentado. Percebe-se, com isso, que a "instituição" não virá apenas de um lugar, mas sim, de "uma cadeia de instituições que apresenta uma estrutura hierárquica” (RICOEUR, 2008, p. 253).

E o que seria essa justa distância apresentada por Paul Ricoeur? Ele mesmo responde (2008, p. 66): “Justa distância, meio-termo entre a pouquíssima distância própria a muitos sonhos de fusão emocional e o excesso de distância alimentado pela arrogância, pelo desprezo, pelo ódio ao estranho, desconhecido". Tem-se que manter um meio termo e, nessa busca, pode ser pensado, uma primeira vez, no elo entre justiça e instituição.

Com a análise feita até agora, já é possível ter uma visão do que, de fato, seja justiça, ou do que se pensa que seja justiça. Para finalizar essas observações sobre o que seria a justiça, Michael J. Sandel traz observações valiosas para tal esclarecimento.

Em sua obra "Justiça - o que é a coisa certa a fazer", o autor trata de algumas visões da justiça, e que merecem reflexão. Ele apresenta o raciocínio moral consequencial, onde as coisas moralmente corretas dependem das consequências da ação (e situa a moralidade nas consequências de um ato que resultará a ação praticada), e que traz como exemplo mais influente o utilitarismo, doutrina criada por Jeremy Bentham, filósofo inglês do século XVIII; mas apresenta também o raciocínio moral categórico, que situa a moralidade em certos requisitos morais absolutos, certos deveres e direitos categóricos, independente de suas consequências, e que tem como mais importante pensador, Immanuel Kant, filósofo alemão do século XVIII.

De acordo com Jeremy Bentham (apud SANDEL, 2012, p. 48), "o mais elevado objetivo da moral é maximizar a felicidade, assegurando a hegemonia do prazer sobre a dor. [...] a coisa certa a fazer é aquela que maximizará a utilidade”. Daí, o utilitarismo seria um princípio de máxima felicidade. Para essa teoria, a maximização da utilidade, tanto por parte dos cidadãos quanto dos legisladores, deve-se analisar aquilo pelo que se sente prazer, e aquilo pelo que se sente dor, pois todos gostam de sentir prazer e de não sentir dor. Uma vez que isso tivesse sido apresentado, chegar-se-ia ao resultado do utilitarismo. Mas essa teoria é 
vulnerável, pois não consegue respeitar os direitos individuais, não atribuindo o valor devido à dignidade humana.

Deste modo, não é a melhor das teorias a ser seguida. John Stuart Mill (apud SANDEL, 2012, p. 63) tentou salvar essa teoria, "reformulando-a como uma doutrina mais humana e menos calculista", conciliando os direitos dos indivíduos com a teoria utilitarista. Para ele, a utilidade deve ser maximizada a longo prazo, e não caso a caso, como defendia Bentham. Ele insiste nas questões de "prazer e dor" como realmente importantes, mas reconhece que "alguns tipos de prazer são mais desejáveis e valiosos do que outros". Essa teoria traz uma reflexão, mesmo que alguns prazeres sejam maiores, há vezes em que se opta por prazeres menores (por exigir um grau de comprometimento e atenção menor - por exemplo, assistir sentado no conforto do sofá a um filme de comédia ao invés de ler uma obra de William Shakespeare). (MILL apud SANDEL, 2012, p. 69)

Essa teoria objetiva o bem ao maior número de pessoas, mas isso é um risco, pois a pergunta que fica é: fazer o bem para a maioria, prejudicando (ou até mesmo dizimando) uma minoria, é o correto a se fazer? Essa é a ideia de justiça que deve ser adotada?

Já para Immanuel Kant (apud SANDEL, 2012, p. 136), ao defender sua teoria, baseada no raciocínio moral categórico, traz uma ideia de direitos humanos universais, e "parte da ideia de que somos seres racionais, merecedores de dignidade e respeito". Ele repudia o utilitarismo. Trazendo as ideias de Kant, Michael J. Sandel (2012, p. 138) diz que “ao basear direitos em um cálculo sobre o que produzirá a maior felicidade, argumenta ele, o utilitarismo deixa esses direitos vulneráveis". O autor diz ainda (SANDEL, 2012, pp. 139140), que é possível aproveitar um pouco a ideia do utilitarismo, mas para inserir na ideia completa que ele propõe. Assim, vale a pena observar:

Kant admite que nossa capacidade de raciocínio não é a única que possuímos. Somos capazes também de sentir prazer e dor. Ele reconhece que somos criaturas sensientes, bem como racionais. Kant quer dizer que respondemos aos nossos sentidos, aos nossos sentimentos. Então Bentham estava certo, mas apenas em parte. Ele tinha razão ao observar que gostamos do prazer e não gostamos da dor. Mas estava errado ao insistir que prazer e dor são "nossos mestres soberanos". Kant diz que a razão pode ser soberana, pelo menos parte do tempo. Quando a razão comanda nossa vontade, não somos levados apenas pelo desejo de procurar o prazer e evitar a dor.

Nossa capacidade de raciocinar está intimamente ligada a nossa capacidade de sermos livres. 
Embora tal afirmação (que se parece correta) de que o utilitarismo pode estar contido na teoria de Kant, este o repudia, conforme destacado por Michael J. Sandel (2012, p. 171):

[...] Kant repudia o utilitarismo não apenas como uma base para a moralidade pessoal, mas também como uma base para a lei. Em seu entender, uma Constituição justa tem como objetivo harmonizar a liberdade de cada indivíduo com a liberdade de todos os demais. Isso nada tem a ver com a maximização da utilidade, que "não deve, em hipótese alguma, interferir" na determinação dos direitos básicos. Já que as pessoas "têm visões diferentes da finalidade empírica da felicidade e do que ela consiste", a utilidade não pode ser a base da justiça e dos direitos. Por que não? Porque basear os direitos na utilidade exigiria que a sociedade afirmasse ou endossasse uma concepção de felicidade em detrimento de outras.

Essa situação imporia a vontade de uns, em detrimento da de outros. Não se pode atribuir um conceito de felicidade, por não ser um conceito exato. Para garantir a dignidade humana é necessário que todos se sintam acolhidos, mesmo que em algum momento suas vontades não sejam recepcionadas, devendo-se garantir que elas existam e sejam preservadas.

Assim, pela visão de Kant, o utilitarismo não deve prevalecer, mas talvez ser mantido, como um complemento à sua teoria, para auxiliar no próprio desenvolvimento de sua teoria do ceticismo, que é "um pouso para a razão humana, onde ela poderá refletir sobre suas incursões dogmáticas", baseada no raciocínio moral categórico, conforme analisado.

Para fechar essa ideia de justiça, Michael J. Sandel (2012, p. 321) consegue sintetizar e, mais que isso, clarear uma ideia do que seja justiça, conforme se pode observar:

No transcurso dessa jornada, exploramos três abordagens de justiça. Uma delas diz que justiça significa maximizar a utilidade ou o bem-estar - a máxima felicidade para o maior número de pessoas. A segunda diz que justiça significa respeitar a liberdade de escolha - tanto as escolhas reais que as pessoas fazem em um livre mercado (visão libertária) quanto as escolhas hipotéticas que as pessoas deveriam fazer na posição original de equanimidade (visão igualitária liberal). A terceira diz que a justiça envolve o cultivo da virtude e a preocupação com o bem comum

O autor supramencionado é adepto da terceira versão, e explica as razões de não aceitar as duas primeiras:

A abordagem utilitária contém dois defeitos: primeiramente, faz da justiça e dos direitos uma questão de cálculo, e não de princípio. Em segundo lugar, ao tentar traduzir todos os bens humanos em uma única e uniforme medida de valor, ela os nivela e não considera as diferenças qualitativas existentes entre eles. 
As teorias baseadas na liberdade resolvem o primeiro problema, mas não o segundo. [...] De acordo com essas teorias, o valor moral dos objetivos que perseguimos, o sentido e o significado da vida que levamos e a qualidade e o caráter da vida comum que compartilhamos situam-se fora do domínio da justiça.

Isso me parece equivocado. Não se pode alcançar uma sociedade justa simplesmente maximizando a utilidade ou garantindo a liberdade de escolha. Para alcançar uma sociedade justa, precisamos raciocinar juntos sobre o significado da vida boa e criar uma cultura pública que aceite as divergências que inevitavelmente ocorrerão. (SANDEL, 2012, p. 321).

Deste modo, a justiça não é um conceito completamente ilimitado, pois deve-se aproveitar, em parte, a ideia do utilitarismo (pois é melhor sentir prazer do que dor), juntando à ideia da liberdade de escolha, mas não apenas isso, deve-se criar uma balança, para que essas ideias sejam aceitas, com o devido respeito às divergências.

Assim, busca-se trabalhar com a questão da justiça como fator de respeito tanto às maiorias quanto às minorias, respeitando-se as diferenças qualitativas entre elas e aceitando as preferências (desde que justificadas e respeitando a dignidade de todos os indivíduos). Com essa ideia, Michael J. Sandel (2012, pp. 322-323) defende que "Justiça não é apenas a forma certa de distribuir as coisas. Ela também diz respeito à forma certa de avaliar as coisas”.

Diante do analisado, torna-se possível uma compreensão mais clara acerca do que seja a justiça; mas também é necessária uma análise da equidade para, em complemento ao conceito já estudado, aí sim, destacar meios adequados a serem adotados para se buscar e se estabelecer a justiça, meios tais, como a mediação e a conciliação.

\section{Equidade como suporte facilitador para proporcionar a justiça}

Uma vez compreendido o conceito de justiça, é importante analisar, mesmo que de forma sucinta, o que vem a ser a equidade, e como ela pode ser utilizada. O estudo sobre justiça e equidade é indissociável da análise dos direitos humanos, pois os temas são extremamente correlatos e, quando se trata das ideias que vêm sendo desenvolvidas no presente trabalho, é impossível estrutura-las sem dar um viés de direitos humanos que, muitas vezes, serve exatamente para fundamentar e embasar a compreensão da justiça e da equidade.

Tanto é que Henry Steiner (apud PIOVESAN, 2013, p. 68) reforça essa ideia:

Muitos dos princípios nos quais o Direito Internacional dos Direitos Humanos está baseado relacionam-se à necessidade de assegurar que não apenas as violações cessem, mas que a justiça seja feita em relação a ambos, vítimas e perpetradores. Estes princípios incluem o direito a um remédio, à 
responsabilização, à punição dos autores e ao pagamento de uma indenização apropriada, bem como a medidas que facilitem a reabilitação da vítima.

Em suma, diversos princípios dos direitos humanos visam garantir a justiça e preservar a integridade de cada indivíduo, que tem garantida a proteção ao acesso à justiça e a uma tutela jurisdicional efetiva.

O que se entende por equidade? Elza Antonia Pereira Cunha Boiteux (2011, p. 332) bem define a equidade como sendo "o procedimento emprestado para corrigir a generalidade da lei, bem como as lacunas decorrentes da omissão do legislado. É um procedimento que se aplica em decorrência do erro ou falha da justiça legal: por esta razão, é superior a ela".

Dessa análise, é possível a compreensão do que seria justo. Significa que o termo "justo" é gênero, de onde se pode extrair duas espécies, quais sejam, a equidade (que tratará das generalidades da lei, e das lacunas) e a lei (que diz respeito à justiça legal).

A equidade "representa um critério hermenêutico, legal e extralegal, de integração do direito escrito, assim como de criação, em domínios limitados, de um novo direito" (CELONE, 2017, p. 92). Com isso, entende-se que ela pode integrar ou complementar determinada legislação, ou mesmo corrigi-la quando deficiente, para o fim de atender às necessidades da sociedade e praticar-se não só a justiça, como a equidade, fazendo-se aquilo que será considerado justo. Desta feita, baseada nos ensinamentos de Aristóteles, a equidade se aproxima do justo, e traz um aspecto superior a uma espécie de justiça (leia-se, justiça legal), pois não basta uma norma regulamentando determinada situação, uma vez que o caso concreto exige uma análise particular, pormenorizada, e que pode trazer, sim, o preceito legal, mas muitas vezes, para ser resolvido, precisará trazer uma interpretação para se fazer o que é justo na hipótese analisada especificamente.

Ademais, John Rawls, em Uma Teoria da Justiça, traz algumas reflexões importantes, destacando que as pessoas não são completamente livres para formar suas convicções, elas devem respeitar parâmetros e os princípios básicos que se fundam na dignidade da pessoa humana, assim, cada vontade não será absolutamente respeitada, mas sim, dentro de um contexto social, desde que haja o respeito aos padrões mínimos sob os quais a sociedade deve viver, pautando-se na Constituição Federal e demais mecanismos de preservação de direitos humanos. Vale destaque sua análise acerca dessa ideia: 
Do ponto de vista da justiça como eqüidade, não é verdade que os juízos de consciência de cada pessoa devam ser absolutamente respeitados; tampouco é verdade que os indivíduos sejam completamente livres para formar as suas convicções. [...] Ao discutirmos a objeção de consciência, observamos que o problema aqui é o de decidir como devemos àqueles que tentam agir seguindo a direção de sua consciência equivocada ( $(56)$. Como ter a certeza de que é a consciência deles, e não a nossa, que está equivocada, e em que circunstâncias eles podem ser obrigados a desistir? Ora, encontramos a resposta para essas perguntas quando assumimos a posição original: a consciência de uma pessoa está desorientada quando ela procura nos impor condições que violam os princípios com os quais cada um de nós consentiria nessa situação. (RAWLS, 2000, p. 577).

Dessa observação pode-se complementar que devem ser respeitadas todas as pessoas, e não cada um tentar impor e fazer valer a sua verdade, ou aquilo que pensa como certo. Mas tal respeito e tais garantias devem observar padrões mínimos e, para tanto, há de se cuidar para que a "consciência" não esteja equivocada, e que observe parâmetros mínimos sob os quais a sociedade deve se organizar, garantindo, assim, uma preservação e proteção de todos.

Não se podem violar os princípios constitucionais nem os previstos em tratados internacionais que versem sobre direitos humanos, sob pena de se incorrer em retrocesso, e se retornar há um período onde nenhuma (ou quase nenhuma) garantia era dada ao indivíduo.

Já é tão difícil compreender o que seja justiça, e trazer a equidade para garantir realmente que essa justiça seja efetiva, e Amartya Sen (2009, p. 320) ainda destaca: “Afirmase com frequência que não só se deve fazer a justiça, mas também 'mostrar que se fez justiça"”. Tem-se que demonstrar que ela foi feita, e isso por vezes é necessário, para que a pessoa que não teve aquela "justiça" que pensava ter possa compreender o porquê de não ter sido atendida em determinado ponto. Essa ideia é importante, pois muitas das vezes é necessário que uma decisão judicial justa seja vista desse modo, pois "se uma sentença inspira confiança e desperta uma aprovação geral, é muito provável que possa ser implementada com maior facilidade" (SEN, 2009, p. 320). Aqui, tem-se a justiça como a razão de decidir.

Como se pode buscar, ou concretizar, aquilo que se entende como justo? Como se fazer a justiça, e garantir a equidade no caso concreto? Será que é possível dizer que a "justiça" é feita para todos? Será que alguns terão mais condições de concretizar a justiça (ou realizar suas pretensões)? São lacunas que precisam ser respondidas.

Num primeiro momento, alguns terão mais dificuldade em concretizar a justiça, quer por suas condições financeiras, quer por possuírem difícil acesso aos meios que garantam a justiça, mas isso não pode ser fator impeditivo para a garantia de concretização da justiça, 
pois todos possuem tal direito, de tutela jurisdicional e de acesso à justiça, garantidos constitucionalmente. Devem ser propiciados aos cidadãos meios para que o acesso à justiça seja, de fato, garantido, e que a justiça seja feita para todos (ou, pelo menos, o direito a ter uma resposta jurisdicional, que pode dar razão, ou não, a quem requereu).

\section{Mecanismos para a concretização do acesso à justiça}

Conforme abordado anteriormente, há meios em que a justiça é observada como a razão de decidir. Tal razão não pode ser vista unicamente sob a ótica da esfera judicial, pois pode ser feita extrajudicialmente (embora haja a mediação e a conciliação judiciais, que visam garantir o acesso à justiça, esses institutos também existem na esfera extrajudicial). É importante observar alguns mecanismos essenciais para a garantia e concretização do acesso à justiça. Sob esse viés, é necessário garantir e observar um senso de justiça, o que é explorado por John Rawls (2000, pp. 630-631) com muita propriedade:

Um senso de justiça é um desejo efetivo de aplicar os princípios da justiça e de agir, portanto, adotando o ponto de vista da justiça. Assim, deve-se estabelecer o que é racional (segundo a teoria restrita do bem) que os membros de uma sociedade bem-organizada afirmem seu senso de justiça como regulador de seu plano de vida.

Partindo de um senso de justiça, é possível a reflexão de meios para se garantir o acesso à justiça e preservar a dignidade da pessoa humana. Como, no universo do Direito, poder-se-ia afirmar se uma decisão é justa e se ela realmente observou e cumpriu os ditames da "justiça"? Ainda continua sob aspecto subjetivo (o que seria justiça para um ou outro?).

Os estudiosos do direito processual civil por vezes questionam: será que a decisão justa é aquela que atingiu os preceitos legais de justiça? Será que é aquela que garantiu o devido processo legal e a igualdade processual? Ou será que vai além? Com essas indagações, é possível observar que não há um aspecto restrito, fechado, para conceituar justiça, a intenção é despertar o questionamento: o que seria justo?

A partir daí, o caso concreto vai possibilitar que a justiça seja (ou não) empregada, garantindo a toda pessoa os direitos básicos inerentes à sua condição enquanto ser humano, e preservando a integridade de cada um, com a realização e efetiva concretização da justiça.

Os direitos fundamentais devem ser garantidos a todos, não podendo ser suprimidos (tratam-se de cláusulas pétreas). Ademais, Elza Antonia Pereira Cunha Boiteux (2008, p. 507) complementa que "Também não é possível desenvolver e proteger as liberdades individuais 
sem proteger os direitos sociais ou proteger os direitos sociais sem garantir uma qualidade de vida adequada". Deve-se observar as nuances do caso concreto, para preservar o indivíduo e proteger a sociedade como um todo, conservando todas as garantias constitucionais.

Para que haja a garantia de efetividade da tutela jurisdicional, é necessário pensar em meios adequados (e não meramente "alternativos") para a resolução dos conflitos e a consequente tentativa de realização da justiça. Quando se diz adequado, busca-se dizer que "não há superioridade da justiça estatal em relação aos demais meios de solução de controvérsias" (DIDIER Jr.; ZANETI Jr., 2017, p. 37). Exatamente por isso, já se mencionou que há meios judiciais e extrajudiciais para a solução dos litígios.

O Código de Processo Civil atual (Lei n. ${ }^{\circ}$ 13.105, de 16 de março de 2015) traz um novo olhar para o direito processual, propiciando um viés muito mais social do que qualquer outro diploma processual civil brasileiro já trouxe. Assim, é necessária uma releitura atenta, que demonstrará o aspecto social e humano nele contidos.

Nesse momento, deve-se analisar os meios pelos quais a justiça pode ser concretizada, que são os autocompositivos e os heterocompositivos. Não se visa, com o presente trabalho, esgotar cada um deles, ou aprofundar o estudo sobre um específico (que merece atenção individual). Tem-se como objetivo apresentar as possibilidades para se concretizar a justiça, e cada um dos meios, e suas particularidades, merecem tratamento amiúde, de forma específica e em trabalho destinado exclusivamente a eles.

Mas não se poderia encerrar a presente explanação, que buscou esclarecer e apresentar elementos para se definir o que seja justiça, sem mencionar os meios pelos quais ela pode ser, de fato, efetivada. Dentre os meios heterocompositivos, destacam-se a arbitragem e o processo. Já em relação aos meios autocompositivos, os destaques ficam por conta das figuras da conciliação e da mediação.

A arbitragem é tida como a "técnica de solução de conflitos mediante a qual os conflitantes buscam em uma terceira pessoa, de sua confiança, a solução amigável e 'imparcial' (porque não feita pelas partes diretamente) do litígio" (DIDIER, 2017, p. 192). Ela é regulada pela Lei n. ${ }^{\circ}$ 9.307, de 1996 (que sofreu alterações pela Lei n. ${ }^{\circ}$ 13.129, de 26 de maio de 2015), e pode ser constituída por meio de um negócio jurídico denominado convenção de arbitragem, que compreende a cláusula compromissória (onde as partes decidem, de forma prévia, que as divergências originárias de certo negócio jurídico serão 
resolvidas através da arbitragem) e o compromisso arbitral (acordo de vontades para submeter uma controvérsia concreta, já existente, ao juízo arbitral, prescindindo do Poder Judiciário).

Para que haja arbitragem, as partes devem ser maiores e capazes, deve versar sobre direito patrimonial disponível e, também, deve haver um ajuste prévio, pela arbitragem. A decisão do árbitro é a sentença arbitral, que é título executivo judicial, é imutável e só pode ser anulada por vício formal. Ela é considerada pela doutrina majoritária como jurisdição.

Esse meio é importante para garantir o acesso à justiça, pois o terceiro, de confiança das partes, auxiliará para a resolução da contenda e, em sendo o caso, determinará a decisão oriunda daquele conflito surgido. Isso tudo, sem a necessidade de se invadir a esfera do abarrotado Poder Judiciário, o que é um ganho para todos.

Há também, daí sim, a possibilidade de se buscar socorro diretamente no Poder Judiciário, através do processo. Em linhas gerais, o processo é o instrumento da jurisdição, e pode ser compreendido como "método de criação de normas jurídicas, ato jurídico complexo (procedimento) e relação jurídica (DIDIER, 2017, p. 36)

Uma vez surgido o conflito, há a necessidade de sua resolução. Quando não se opta pela arbitragem ou por meios autocompositivos, há a opção pelo processo, que buscará, através da figura do magistrado, garantir o direito à tutela jurisdicional, caso a parte tenha realmente razão ao provocar o Judiciário. Atualmente, há um incontável número de processos tramitando, o que acaba trazendo certa morosidade à justiça, ou ao acesso a ela, pois casos que poderiam ser resolvidos rapidamente demoram muito além do razoável, em razão do excesso de processos e à sobrecarga do Judiciário (onde faltam servidores, magistrados etc.).

Deve haver uma conscientização geral da sociedade para buscarem meios que possam, efetivamente, dar-lhes uma resposta (positiva ou negativa, mas é preciso dar um retorno ao que se busca). Nesse momento surge aquilo que é tido como a "menina dos olhos" do CPC/2015, que é o meio autocompositivo, notadamente nas modalidades da mediação e da conciliação. Essas modalidades visam encorpar o direito e o acesso à justiça para todos, como um modo de estabelecimento de um diálogo entre as partes, para que a solução se resolva e tenha-se aquilo que o Conselho Nacional de Justiça chamou de "relação ganha-ganha".

A autocomposição corresponde a uma solução (ou decisão) do litígio por meio dos próprios litigantes, e é considerada uma "solução altruísta do litígio". O Estado propicia esse mecanismo para que as próprias partes se resolvam, e só o procurem caso precisem; e mesmo que procurem a tutela estatal, ele ainda tentará fazer com que elas se resolvam (pois, mesmo 
na esfera do Poder Judiciário, com um processo, é possibilitado a qualquer das partes da relação jurídica processual, e a qualquer momento, requerer a busca pela autocomposição).

Antes do advento do CPC/2015, a Resolução n. ${ }^{\circ}$ 125, de 2010, do Conselho Nacional de Justiça, era o instrumento mais importante que buscava garantir a mediação e conciliação para a solução adequada dos conflitos. O CPC/2015 incorporou muitos dos preceitos lá previstos, e a Lei de Mediação (Lei n. ${ }^{\circ}$ 13.140/2015) foi fruto daquela ideia arraigada lá em 2010. Dos dois instrumentos normativos que surgiram em 2015, com suas inovações, a Resolução do CNJ precisou ser alterada (em 2016), para fins de adequação.

Para que a autocomposição seja possível, é necessário observar alguns requisitos: que as partes sejam capazes, que o direito seja disponível (pelo menos quanto à forma de seu exercício) e que haja o consenso (consenso é essencial para que se chegue a um acordo).

Há diversos meios de solução de conflito através da autocomposição, como a negociação, a transação (esses dois feitos diretamente pelas partes, sem auxílio de um terceiro), a mediação e a conciliação (já esses, com o auxílio de um terceiro, e possuem semelhanças, mas também diferenças).

Vale destacar os dois últimos meios: mediação e conciliação. A diferença entre esses dois meios é sutil (do ponto de vista prático, pode ser que seja até inexistente, mas há pontos particulares em que reside tal diferença). Fredie Didier Jr. (2017, p. 308) traz o seguinte:

O conciliador tem uma participação mais ativa no processo de negociação, podendo, inclusive, sugerir soluções para o litígio. A técnica da conciliação é mais indicada para os caos em que não havia vínculo anterior entre os envolvidos.

O mediador exerce um papel tanto diverso. Cabe a ele servir como veículo de comunicação entre os interessados, um facilitador do diálogo entre eles, auxiliando-os a compreender as questões e os interesses em conflito, de modo que eles possam identificar, por si mesmos, soluções consensuais que gerem benefícios mútuos. Na técnica da mediação, o mediador não propõe soluções aos interessados. Ela é mais indicada nos casos em que exista uma relação anterior e permanente entre os interessados [...]. (itálico do autor).

Dessa observação que, inclusive, está expressa no art. 165, $\S \S 2^{\circ}$ e $3^{\circ}$, do CPC/2015, pode-se verificar a sutil diferença entre um e outro, enquanto que, na mediação, o mediador não tem a possibilidade de apresentar sugestões, devendo buscar o restabelecimento do diálogo, da comunicação, entre os contendores, na conciliação, o conciliador pode apresentar sugestões para que as partes, compreendendo claramente o que foi apresentado, possam chegar a um resultado satisfatório do conflito que havia surgido. Vale destacar que, nem 
medidor, nem conciliador, pode impor aquilo que entende como o correto, proferindo decisão e substituindo a vontade das partes, que é soberana.

A mediação e a conciliação podem acontecer extrajudicialmente, o que é um facilitador para as próprias partes, pois tira o caráter judicializado (muitas das vezes a esfera judicial intimida as partes e, se feita extrajudicialmente, traz um conforto maior para as partes). Mas elas também podem ocorrer (o que tem se observado com bastante frequência) de forma judicial (e, aqui, os mediadores e os conciliadores são considerados auxiliares da justiça), o que é louvável, pois a visão mais antiga é aquela de se buscar o Poder Judiciário para que o magistrado diga quem tem direito (e quem não terá).

Agora, antes de o magistrado necessitar responder quem tem (ou não) razão, ele deve possibilitar mecanismos para que as partes tentem chegar a uma solução, esclarecendo-se as informações que se fizerem necessárias e, no caso da conciliação, inclusive sendo apresentadas sugestões, que podem ajudar a parte a ter a sua satisfação de modo mais efetivo.

Sobre cada um dos meios autocompositivos destacados é possível desenvolver um trabalho específico, e a intenção de apresentação nesse contexto, é no sentido de que é possível se propiciar a justiça, garantir a justiça, preservar a equidade, e as partes saírem satisfeitas daquele conflito que surgiu (aqui, entendendo a justiça como a razão de decidir).

Não é preciso uma decisão imperativa, mas sim, antes disso, uma decisão que propicie às partes a sua satisfação, e sejam novamente postas em contato, através do restabelecimento da comunicação (imagine-se a situação de vizinhos, que moram lado a lado, há anos - muitas alegrias e tristezas já foram presenciadas -, pode ser que eles vivam muitos anos mais, no mesmo local. Busca-se uma harmonização, para que a convivência não seja um mero fardo entre um e outro).

Com isso, a ideia de justiça se faz a cada dia mais viva, pois há meios heterocompositivos, mas também meios autocompositivos, que devem ser tratados com seus devidos valores, pois a boa aplicação da mediação e da conciliação para a solução de conflitos é essencial para a evolução da justiça, e a própria evolução da sociedade, garantindo a preservação da dignidade humana e a proteção de todos os direitos que lhe são inerentes.

\section{Conclusão}

Falar de justiça é um dos maiores desafios que se pode enfrentar, pois todos sabem (ou imaginam) o que é, mas materializar, expressar, demonstrar o que seja, 
fundamentadamente, é um papel muito mais árduo. Não é possível falar de justiça sem remeter à filosofia antiga, quando apresentados conceitos iniciais por Aristóteles.

Mas também não se pode restringir apenas àqueles conceitos, que são a base, pois o mundo passou por profunda transformação com o avançar dos séculos. Conflitos, guerras, divergências aconteceram e, com isso, os estudiosos trouxeram a evolução do conceito de justiça, para garantir a integridade da sociedade. Conceitos de direitos humanos, de preservação à dignidade da pessoa humana, de garantia de uma sociedade mais justa e solidária surgiram, e devem ser protegidos por todos.

Pesquisar sobre as teorias que desenvolvem a justiça, destacar que aquilo que se entende como justiça pode o ser para um, mas para outro, há pensamento em sentido contrário, em razão da teoria que adota. O importante é que todos seguem (ou devem seguir) um mesmo sentido, de preservação de todos, de respeito às diferenças, de proteção às formas de expressão.

No Brasil, a diferença socioeconômica e cultural é muito grande, até mesmo por se tratar de um país com dimensões continentais, e cada indivíduo da sociedade deve ser respeitado, cada expressão (desde que em conformidade com a Lei Maior, a Constituição Federal de 1988) deve ser ouvida e respeitada, cada manifesto deve ter sua atenção (e não simplesmente ser deixado ao relento).

Nesse sentido, é necessária a busca pela justiça, aqui entendida como a busca pela solução de um conflito. Nesse momento, surgem diversas figuras, tanto com viés heterocompositivo (como nos casos da arbitragem e do processo) quanto com viés autocompositivo (como nos casos da mediação e da conciliação). Deve-se, antes de partir para o enfrentamento, tentar o diálogo, e possibilitar que as partes resolvam suas pendências e (ambas) saiam satisfeitas com o que foi resolvido.

Assim, é importante o estudo acerca da justiça, e dos mecanismos para sua obtenção. A mediação e a conciliação ganham evidência como mecanismos concretos para a realização e efetivação da justiça e, mais do que isso, protegendo os conceitos mais sublimes de justiça e garantindo a dignidade da pessoa enquanto ser humano.

\section{Referências}


- BRASIL. CÓDIGO DE PROCESSO CIVIL. Disponível em $<<$ http://www.planalto.gov.br/ccivil_03/_ato2015-2018/2015/lei/113105.htm〉>. Acesso em 02/07/2019.

- BRASIL. CONSTITUIÇÃO DA REPÚBLICA FEDERATIVA DO BRASIL DE 1988.

Disponível em <<http://www.planalto.gov.br/ccivil_03/constituicao/constituicao.htm〉>. Acesso em 02/07/2019.

- BOITEUX, Elza Antonia Pereira Cunha. Educação e valores ambientais. Revista da Faculdade de Direito da Universidade de São Paulo, São Paulo, v. 103, jan./dez. 2008, p. 503 $-516$.

- BOITEUX, Elza Antonia Pereira Cunha. "Variações sobre o conceito de equidade". In. Adeodato, João Maurício, et. Alii (orgs.) Filosofia e teoria geral do direito: estudos em homenagem a Tércio Sampaio Ferraz Júnior. Quartier Latin, 2011, p. 332.

- CELONE, Cristiano. A equidade no direito administrativo italiano. Revista de Processo. Vol. 269, Revista dos Tribunais, julho/2017, p.92.

- CONCURSO DA MAGISTRATURA. Noções gerais de direito e formação humanística. Coord. Jerson Carneiro Gonçalves Jr., José Fábio Rodrigues Maciel. São Paulo: Saraiva,

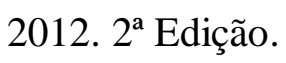

- DIDIER JR., Fredie. Curso de direito processual civil: introdução ao direito processual civil, parte geral e processo de conhecimento. Volume 1. Salvador: Ed. Jus Podivm, 2017.

- DIDIER JR., Fredie; ZANETI JR., Hermes. Justiça multiportas e tutela constitucional adequada: autocomposição em Direitos Coletivos. In. JUSTIÇA MULTIPORTAS. Mediação, Conciliação, Arbitragem e outros meios de solução adequada de conflitos. Coord. Hermes Zaneti Jr. e Trícia Navarro Xavier Cabral. Salvador: Jus Podivm, 2017. p. 35 - 66.

- FERRAZ JÚNIOR, Tércio Sampaio. Estudos de filosofia do direito: reflexões sobre o poder; a liberdade, a justiça e o direito. São Paulo: Atlas, 2009.

- GONÇALVES JR., Jerson Carneiro. Filosofia do Direito. In. CONCURSO DA MAGISTRATURA. Noções gerais de direito e formação humanística. Coord. Jerson

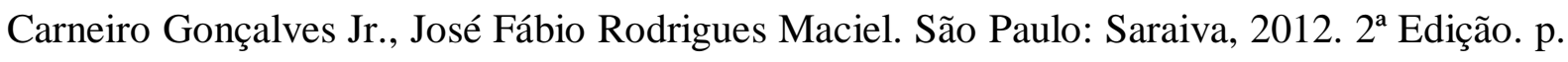
$185-317$.

- HABERMAS, Jürgen. A Inclusão do Outro - estudos de teoria política. São Paulo: Edições Loyola, 2002. 
- JUSTIÇA MULTIPORTAS. Mediação, Conciliação, Arbitragem e outros meios de solução adequada de conflitos. Coord. Hermes Zaneti Jr. e Trícia Navarro Xavier Cabral. Salvador: Jus Podivm, 2017.

- PIOVESAN, Flávia. Direitos Humanos e o Direito Constitucional Internacional. 14. ed. São Paulo: Saraiva, 2013.

- RAWLS, John. O liberalismo político. São Paulo: Ática, 2000.

- RAWLS, John. Uma teoria da justiça. São Paulo: Martins Fontes, 2000.

- RICOEUR, Paul. O justo ou a essência da Justiça. Lisboa: Editora Piaget, 1995.

- RICOEUR, Paul. O justo 2: justiça e verdade e outros estudos. São Paulo: Martins Fontes, 2008 .

- SANDEL, Michael J. Justiça - o que é fazer a coisa certa. Rio de Janeiro: Civilização Brasileira, 2012.

- SARLET, Ingo Wolfgang. Dignidade da Pessoa Humana e Direitos Fundamentais na Constituição Federal de 1988. Porto Alegre: Livraria do Advogado Editora, 2011. $9^{\text {a }}$ Edição.

- SEN, Amartya. A Ideia de Justiça. São Paulo: Editora Schwarcz Ltda., 2009. 